\title{
AN EXPERT SYSTEM FOR VALUATION OF RESIDENTIAL PROPERTIES
}

\section{CONALL BOYLE}

\section{What is an 'Expert System'?}

There has been much discussion in the popular media recently on the topic of Expert Systems (for example the BBC 'Horizon' of 21st March, 1983, or the Sunday Times, 1st May, 1983). Expert Systems are 'computer programs that can acquire knowledge from experts and make it available in the form of advice to those less skilled' (Landsdown, 1980). Such expert systems are one of the main building blocks of the 'fifth generation' computers, which are under development, with massive government encouragement, in Japan.Valuation is one of the most important professional skills which the General Practice surveyor has to offer. Could this skill be transferred to a computer, bypassing the need for trained human intervention? Is an expert valuation system possible, or even likely? In this paper, I hope to show that such a computer-based valuation system is indeed a possibility. However, such a development need not fill the profession with alarm. The skill of the valuer will still be required; but the nature of the task of valuation may be changed significantly.

\section{What an expert system for valuation might look like}

You, the valuer, have been asked to value a three-bedroomed semi-detached house in Hall Green, an up-market area of Birmingham. Instead of visiting the property, you conduct the dialogue shown in Figure 1 (see over) with your computer. After you have entered all the details, the computer will give you a print-out which could look like the example shown in Figure 2 (see over). The dialogue contains elements which any valuer can recognise as value-significant items. The questions that must be asked are: valuation?

- can such information be digested by a computer and turned into a

- if it can, how accurate will the results be?

In this paper, I will describe an experiment to carry out Valuations by computer'. The degree of success attained does not mean that we can expect to see the immediate demise of the valuer. However, it does indicate the potential for computerised valuations. 
Figure 1 \& 2: Print-out of valuation. The computer digests the information from this dialogue and produces the result shown

PROPERTY VALUATION BY COMPUTER

THIS PROGRAM WILL ESTIMATE THE SELLING PRICE OF DOMESTIC PROPERTIES IN THE BIRMINGHAM AREA, INCLUDING SOLI HULL AND SUTTON COLDFIELD.

PLEASE ENTER DETAILS OF THE PROPERTY, IN REPLY TO THE QUESTIONS THAT FOLLOW. PRESS 'RETURN' AFTER YOU ENTER A NUMBER (YOU WILL NEED TO HAVE THE A TO Z GUIDE TO ANSWER ONE OF THE QUESTIONS).

-> PLEASE FIND THE A TO Z STREET GUIDE AND LOOK UP THE REFERENCE NUMBER FOR THE ADDRESS OF THE PROPERTY THIS WILL BE IN THE FORM ... 2 B 72 PLEASE ENTER AS 2,B,72 ? $\underline{\mathbf{2}, \mathbf{B}, 72}$

-> WHAT TYPE OF PROPERTY?

$$
\begin{aligned}
& 1 \ldots \text {...SEMI-DETACHED } \\
& 2 \ldots \text { DETACHED } \\
& 3 \text {... LINK-DETACHED } \\
& 4 \text {... BUNGALOW (DETACHED), CHALET } \\
& 5 \ldots \text { TERRACED, TOWN HOUSE,MEWS } \\
& 6 \ldots \text { VILLA } \\
& 7 . . . \text { COTTAGE } \\
& 8 \ldots \text { FLAT } \\
& 9 . . . \text { MAISONETTE }
\end{aligned}
$$

$\rightarrow$ AGE OF PROPERTY IN YEARS ? 1

$\rightarrow$ HOW MANY BEDROOMS? ENTER NUMBER ? $\underline{\mathbf{2}}$

-> HOW MANY RECEPTION ROOMS ? $\underline{\mathbf{3}}$

-> WHICH OF THE FOLLOWING BEST DESCRIBES THE CONDITION OF THE PROPERTY

$$
\begin{aligned}
& 2 \text {... IN NEED OF SOME RENOVATION } \\
& 1 \text {... EXCELLENT THROUGHOUT }
\end{aligned}
$$

0 ...ABOUT AVERAGE

ENTER NUMBER ? 1

-> WHAT SORT OF GARAGE

$$
\begin{aligned}
& 0 \ldots \text { NONE } \\
& 1 \text {...SINGLE GARAGE } \\
& 2 \ldots \text { DOUBLE GARAGE } \\
& 3 \text {... PARKING SPACE }
\end{aligned}
$$

ENTER NUMBER 71

-> TYPE OF TENURE

0 ... LEASEHOLD

1.... FREEHOLD

-> CENTRAL HEATING ?

O...NONE

1 ...FULL CENTRAL HEATING

2 ... PART CENTRAL HEATING

$\rightarrow$ DOUBLE GLAZING ?

0 ... NONE

1 ... FULL

ENTER NUMBER ? 1

2 ...PART

ENTER NUMBER ? 1

-> OTHER DESIRABLE FEATURES, SUCH AS SECOND BATHROOM, LAUNDRY ROOM, OUTHOUSES,

LARGE GARDEN, DELIGHTFUL VIEW
1 ... IF PROPERTY HAS SUCH FEATURE(S)
0... IF NOT

ENTER NUMBER ? 1

FOR THE PROPERTY DESCRIBED AS -

SEMI-DETACHED, FREEHOLD

1 YEARS OLD, IN VERY GOOD CONDITION, WITH 2 BEDROOMS, 1 RECEPTION ROOM, SINGLE GARAGE, FULL CENTRAL HEATING, FULL DOUBLE GLAZING, AND HAVING OTHER DESIRABLE FEATURES,SITUATED AT A TO Z LOCATION 2 B 72 "THE ESTIMATED SELLING PRICE IS*

\section{$£ 28,564$}

NB THIS FIGURE IS SUBJECT TO AN ERROR OF UP TO 10\%, AND MAY VARY BECAUSE OF PARTICULAR CIRCUMSTANCES.) 


\section{What are the requirements for an expert system?}

The requirements for an expert system have been described most notably by Professor Donald Michie (Michie, 1979), who came to the subject via Artificial Intelligence. But such is the newness of the subject that theoretical analysis is somewhat sparse. Instead we must infer the requirements of an expert system by reference to examples. Expert systems have been developed in many areas. Examples in the field of medical diagnosis abound. For example, in deciding which of a range of seven types of rheumatism might be present in a patient, the so-called 'EXPERT' program, given details about the patient, produces diagnoses which are correct 94 per cent of the time (Lindberg, 1980). In horticulture, the diseases of soya beans can be identified 'by computer' with similar success (Michalski, 1980).

In general these expert systems require that an agreed set of rules be implemented as a computer program. The method of discovering the rules varies. It sometimes involves a team of the expert professionals formulating the rules. Another technique is for an 'information engineer' (the name given to the new breed of expert in expert systems) to make an informed guess. An important point to note is that any such rules must be computer-programmable, that is expressable in a numeric or categorical way. The entire validity of expert systems depends crucially on the capture of the true nature of the procedure of the professional experts. Only then can conversion of the rules into a form suitable for programming be undertaken.

The 'rules' for valuation of residential properties are suggested in the standard student textbooks. We are reminded that valuations are normally carried out by using the comparable method (Millington, 1982). The valuer should have regard to the general features of the property, noting particularly the presence of such attributes as central heating, scullery, etc (Lawrence, 1971). An important feature of this method of valuation is the need to keep records of comparable properties, hence the name for the technique. It is sometimes argued (Wood, 1973) that valuation is nothing more than glorified guesswork; that there are no rules. I do not believe that this is the case. Although most practising valuers would have difficulty in formalising the rules by which they operate, there is an underlying rationality. By combining long experience with an intimate knowledge of the local market, and an awareness of national trends, the valuer can employ that most subtle and yet powerful of computers, the human brain, to come up with the right valuation.

But because the human brain and the computer operate in such different ways, it might seem that further progress is impossible. A model of what contributes to a valuation doubtless exists inside the mind of the valuer. But the computer cannot (as yet) read this 'brain-map' and translate it into programmable form. To achieve a computer-acceptable model, we need to look anew at the comparable method of valuation.

\section{Developing a model of value - the Hedonic Index technique}

Why do the prices of houses vary? The answer given usually refers to the attributes and location of the property. This can be formalised into a set of specific items which are said to be value-significant. Many valuers make use of simple single variable formulae. Selling price is often estimated from square feet of floor area, by a formula such as: 


$$
P=\text { constant }+ \text { rate } \mathrm{x} \mathrm{sq.} \mathrm{ft}
$$

where the 'constant' might represent site value and 'rate' is the 'cost' of each additional square foot. (This is also known as a 'scale' and 'variant' formula). Such simple formulae are of limited use, a fact which can be confirmed with any practising valuer who has tried them. To adequately describe the factors which are significant in determining market price it is necessary to describe and test a model which combines such factors in a mathematical form. The simplest (and therefore most popular) model takes the form:

$$
\begin{gathered}
P=b_{o}+b_{1} * X_{1}+b_{2} * X_{2}+b_{3} * X_{3}+\ldots \\
\text { where } P \text {-- price to be explained. } \\
. X_{1}, X_{2}, X_{3} \text {, etc are measurable factors, such as age, } \\
\text { numbers of bedrooms, square feet of floor area. (Further } \\
\text { details on factors will be given later in Section } 5 \text { below.) } \\
b_{1}, b_{2}, b_{3} \text {, etc are 'rates' for each of the factors. } \\
b_{0} \text {, is the constant. }
\end{gathered}
$$

For obvious reasons, (2) is called an additive model. We can also have a multiplicative model:

$$
P=b_{0} * X_{1} * X_{2} * X_{3} *
$$

Here the elements are the same as (2), but combined differently.

The reasons for choosing one of these models, or selecting amongst the many other possibilities, is really a matter of Occam's razor. It is best to choose the simplest model which best fits the known facts. The method for testing the validity of the model and establishing the 'rates' for each factor is Multiple Regression Analysis (MRA). As this is a standard statistical technique, it will not be described here. Most advanced textbooks on statistics give an account of MRA (see for example Johnson and Leone, or Imam and Conover, pp. 470-89, which gives an example related to valuations of domestic property). In practical terms, what is needed is a lot of data on 'comparable' property, adequately described, and access to a computer which can run an MRA package. The task is then to convert the data into machine-readable form, and to submit it to the MRA program. The results of the computer run will indicate whether the model is valid, and if so what rates to apply to the various factors.

This method of breaking down the market price of a property into elemental prices or 'rates' for its various attributes is called the Hedonic Index technique. It was applied originally by economists (Grillches, 1967) to consumer products such as motor cars and refrigerators. Urban economists, too, have made much use of the technique, using house prices as indicators of values which they are testing. An excellent study of the housing market in Edinburgh has been undertaken (Richardson, 1975). A source of data used was the Sasines register, a public record of all property transactions required by Scottish law. The chief motivation for urban economists undertaking these studies is to test theories of value. In the case of the Edinburgh study, it was shown that height above sea-level is value-significant.

Since 1972 there have been dozens of Hedonic price studies on housing. MacLennan (MacLennan, 1977) refers to several. These studies have produced a great deal of insight into which factors are significant in assessing 
market price. Despite its potential usefulness for valuers, the technique appears to have remained the preserve of urban economics (with the possible exception of Byrne and Bowcock, 1974). Building a Hedonic price index for housing is thus far from new, and valuers can be confident that it is a well proven technique. Shenkel (Shenkel, 1978) in his well-presented textbook on Real-Estate Appraisal, devotes an entire chapter to 'Valuation by Statistical Inference'. In effect he shows how to apply the Hedonic index technique to residential property valuations. His objective is not so much to get the computer to carry out valuations. Rather he illustrates how to make use of the results in order to better understand the factors affecting value. His description of MRA is most useful, especially as it is given in terms familiar to valuers (but with an American slant, of course).

In the analogous field of rent assessment there have been two recent studies which make use of MRA. In a major study of the activities of the Rent Officer in the West Midlands, Doling ami Davies (1981) examined several hundred actual decisions made on 'fair' rents. They concluded that either the rent officer was acting in a measurably unfair way, or that he had access to information not given in the rent assessments. The application of MRA to rent reviews on commercially-let shops is described by Baum (1982). Turning the results from a hedonic price index study into a computer program to carry out valuations presents little difficulty. By means of an interrogation routine, the user identifies the features of the property. Inverting the model enables the computer to work out a predicted selling price. At this final, crucial stage, it may be necessary to do some fudging of the results. It may be felt essential to include some factor which is generally considered value-significant, even though the MRA does not register it as such. Another problem which frequently arises is lack of statistical significance due to smallness of sample. One way of overcoming this is to combine together results from different subsets which share common characteristics.

\section{A case study: developing an expert system for valuation}

In 1979 I undertook a large scale study of house prices in the Birmingham area; this was repeated in 1982, for a single suburb. (In the second study, the work was ably undertaken by a project student, Mr David Wood.) What follows is a description of these studies.

\subsection{Database}

Data on transactions in the housing market are obtainable from many sources - estate agents, taxation offices, Building Societies. A problem which is common to many sources is confidentiality. The actual price paid is felt to be a personal matter between the purchaser and his financial mentors, and should not be made freely available. Estate agents may be willing to help the genuine researcher, but do not, individually, turn over a sufficient volume of properties for a satisfactory statistical sample. Because of these difficulties, and for the reasons of speed, convenience and cheapness, the source of data used in these studies was house-for-sale advertisements in the local evening newspaper (or estate agents' particulars in the case of the localised study). In the 1979 study details of 519 properties were taken from a single issue of the evening paper. In the 1982 study 170 property details were obtained from estate agents during a single week. In addition to the information given in the advertisements, locational co-ordinates were recorded. Map reading also revealed other local information. 
At first glance advertisements might seem an unlikely source of data for a study with scientific pretensions; but further enquiry reveals that advertisements are inmost respects just as good as the alternatives, and in some ways are markedly superior.

To deal with the recurrent criticism first: Should you not use selling price"? Selling price would be ideal, but it has been shown (Byrne and Bowcock, 1974) that asking price and selling price are very closely correlated (index of determination 0.989). So asking price is, as might be expected, a close surrogate of selling price.

Do advertisements tell the truth'? Despite being written in the main by those profligates of language, estate agents, advertisements $d o$ tell a truthful story. This was established, in part, by means of a random survey among the data. But a moment's reflection demonstrates that falsehoods in advertisements would be self defeating. An advertisement is an invitation to inspect. If a property is described as detached, when it is terraced, it fools no-one. Truth in this case should be self reinforcing.

What do advertisers leave out? Negative features are often omitted, and this is undoubtedly a drawback of this source. But some of these undesirable aspects can be inferred in other ways. Using a map, it is possible to spot which houses are situated on a busy main road, near a railway, etc.

Are advertisements representative"? In order to form a sound view of the housing market in a given area, it is necessary to obtain information on a representative cross-section of types and locations. By comparing the proportions of types found in our studies with Census figures for the area, it was found that advertisements give a very fair picture of the housing market. (In contrast, Building Society figures showed a very unbalanced picture, with more expensive properties over-represented.)

On the positive side, advertisements offer some unique advantages as a source of data:

- Since each word has to be paid for, each is chosen with rare care. The fact that some feature is mentioned in an advertisement may be prima facie evidence that it is value-related.

- Since it is market price that we seek to explain, a 'snap-shot' of the state of the market is needed. Values change with time, and a collection of deals from different points in time may be inadequate. Only advertisements can give upto-date at-the-moment picture.

(These last points are elaborated by Doling, 1978.)

\subsection{Coding the data - house attributes}

The information given in the advertisements cannot be fed directly to the MRA program. It first has to be coded. In some cases this represents little problem. Age and number of bedrooms are numeric variables already. When confronted with categorical data such as type of house - Semi, Detached, Bungalow, the technique is to code on a 'dummy' variable. This dummy takes on a value of 1 or 0 depending on whether or not the property exhibits this characteristic. So variable $X_{1}$ in formula (2) could relate to a bungalow. If the property is a Bungalow score 1 , otherwise score 0 . (There arc some technical problems with both dummy and measured variables, which are explained in Imam and Conover.) The original list of variables related to house attributes were:

SEMI, DETACHED, BUNGALOW, TERRACED, FLAT, MAISONETTTE (house types) 
1BED, 2BED, 3BED, 4BED, 4 + BED(numbers of bedrooms)

CENTRAL-HEAT, DBL-GLAZE, GARAGE-SINGLE, GARAGE-DBL

(other features)

CONDITION (+1: good, -1 : bad), AGE (in years)

FREEHOLD (1: yes, 2: no), SELLER (agent or private)

In the later study, data on square feet of floor area, rateable value, type of roadway, plot size, plot frontage and orientation of the house were also collected and coded.

This is a list which most valuers would recognise as being significant in determining market price. It is consistent too, with the previous hedonic index studies.

\subsection{Coding the data: location}

Without doubt location is the single most important factor in determining market value. Experience shows that two otherwise identical houses, separated by a few miles, can vary in price by as much as 50 per cent. Any model must give location an extensive treatment. For the urban economists, the favoured method is to measure some known 'socio-economic status' (SES) variable for the ward or neighbourhood where the property is located. Thus, for example, the rate of unemployment, or the rate of two cars per household, can be used to measure the desirability or otherwise of the location. Another popular measure used to value location is distance from the Central Business District (CBD). Both methods have been widely used with some success. Neither SES or distance to CBD are particularly suited to the task in hand - building a model to value residential property. SES indicators are based on census data for fairly large areas, and can be ten years out-ofdate. Distance to CBD may be appropriate for valuing commercial property, but is not nearly so important for houses. This is especially true for the West Midlands conurbation, with its multi-centre shopping and employment patterns. Following the lead given by Richardson in Edinburgh, and Byrne and Bowcock in St Albans, I decided to carry out a Trend Surface Analysis (TSA) to describe the variation of values with location. TSA is a method of determining the shape of a surface - its contours - based on a scatter of spot heights. In mathematical terms, it means fitting a polynomial in $x$ and $y$ (the co-ordinates) to the spot heights (or property values, in this case).

The starting variables for TSA are the $x$ and $y$ co-ordinates of each property. From these the computer can calculate the higher orders; $x$ squared, $x$ times $y$, $y$ squared, and so on up the orders of powers and cross-products. In this study calculations were made up to the fifth order.

\subsection{Model polishing}

The data was analysed by MRA using the SPSS (Statistical Package for Social Scientists) package. This is a package which is widely available for use on large main frame computers. It allows for many recodes and recombinations of variables, as well as simple statistical calculations. Its main interest in relation to the current investigation is the regression analyses which are possible. Micro-computers do not as yet offer such a comprehensive and powerful statistical package, but certainly soon will. Various subsets of the house attribute and location variables were tried out using the MRA program. In addition, different models, additive, multiplicative and hybrids, were tried. The objective in all this was to get a 
model which seems plausible and which explains the facts as fully as possible. In the end the simplest additive model proved to be as good as any of the more complicated models. The criterion for assessing the explaining power of a model in MRA is the multiple coefficient of determination, usually labelled ' $R$ squared'. For the large scale (1979) survey, the results showed an $R$-squared value of 0.79 , with a standard error of $£ 3,723$. The value of 0.79 indicates that the model is explaining 79 per cent of the variability in prices. In other words, on the basis of the information given in advertisements it is possible to account for 79 per cent of the variations in price between houses. This leaves a substantial 21 per cent to be explained. Possible reasons for the unexplained variation might be:

— desire of sellers for a quick, or slow but profitable, sale.

- mis-specification in the advertisements.

- quality differences unaccounted for.

- the inherent imperfection in the housing market, where buyers and sellers act without total knowledge.

— problems with using asking rather than selling price.

The standard error of $£ 3,723$ indicates that the model can be expected to predict prices to within $£ 2,400$ more often than not, or that the maximum likely error we can expect is about $£ 7,500$. (These figures are based on the Normal Distribution.) To explain 79 per cent of the variations found in the price of houses, or to achieve an error likely to be in the order of $£ 2,400$, is not very impressive. It certainly would not be acceptable to professional valuers. The subject of errors is not one which valuers like to discuss, although an indication of an acceptable level was given in Singer and Friedlander v John D. Wood, where it was stated that errors in excess of 10 per cent either side, exceptionally 15 per cent, would indicate negligence. My own informal probings amongst valuers suggests that an error of less than 5 per cent is to be expected. The computer program described here does not as yet match these levels. In the later (1982) study much better figures were achieved. An R-squared of 0.91 with a standard error of $£ 2,383$ was obtained. Although this is still not acceptable, it does represent a major improvement on the first study.

Despite the apparent shortcomings of the model in this case, it is worth remembering what has been achieved. The model as described is capable of producing valuations to within a few $£ 1,000$ 's of the true value. This can be done at minimal cost, and in a few minutes. It also covers a very large area - the entire Birmingham Metropolitan District, covering approximately 250,000 properties. No single human valuer could hope to match this breadth of coverage.

\subsection{Testing the valuation program}

The rates for each of the variables used in the MRA were calculated by the computer. A full list is given in Table 1. In statistical language these 'rates' are called the regression coefficients, or $B$ values. Calling them 'rates' is really an interpretation of the nature of these values, but one which is justified. An encouraging feature of these rates was their unsurprising magnitude. A value of $£ 2,097$ for garage, or $£ 800$ for freehold over leasehold is very much in line with common-sense, or the consensus view of valuers. The results for the Trend Surface Analysis are shown as a price-contour map in Figure 3 (see page 282). Again there are no surprises - the theoretical 
map corresponds with the accepted 'good' and 'less-desirable' areas. It is always encouraging when elaborate statistical techniques yield such results. Using the results of the MRA, an interrogation program was devised. The dialogue in Figure 1 shows part of the actual interaction between user and computer. When all the values have been entered, the computer calculates the predicted selling price by applying the rates for each factor which were found using the MRA.

Testing the program took the form of trying out actual properties, taken at random from whatever source came to hand. This informal and strictly $a d$ hoc procedure confirmed the theoretical analysis. About half the results were quite close; the rest gave an unacceptably high error.

\subsection{Multi-collinearity}

One of the most serious problems that can arise when using MRA is known as multi-collinearity. Although the textbook explanations are somewhat intimidating (see for example Huang p. 149) in essence it is quite understandable. Multi-collinearity poses the question: are we really measuring what we think we are measuring? For example, suppose that 'Bungalow' yields a low valuation coefficient. It could be that most of the bungalows in our data set were on an unattractive estate; hence 'bungalow' is measuring the environment, not the type of building. Multi-collinearity can be detected using the simple two-way correlation coefficients between each of the explanatory variables. The computer will readily provide these - but a practical problem is the amount of data generated ( $n$ squared divided by two, where $n$ variables per property are used). In the case of the present study, about 200 of these two-way coefficients were required. Huang suggests that so long as:

$$
r j j<R
$$

ie the two-way coefficients are less than the overall correlation coefficient, then the multi-collinearity is not too serious.

In the study described in this paper one group of variables exhibited an unacceptable degree of multi-collinearity. Eight (out of a total of 180) variable pairs in the Trend-Surface Analysis of Figure 3 showed a value in excess of $R$. The main culprits were combinations of $Y$, the North-South distances from datum. It is not altogether surprising that $Y, Y$ squared and $Y$ cubed should be correlated.

The variables concerned with house attributes were all well within the limit, although some showed higher values than others. For example the pair Central heating with Garage had a value of 0.29 compared to the overall $R$ of 0.89 . This could indicate that houses with central heating usually have a garage. The rate for one or other may thus be too high or too low.

How disastrous is multi-collinearity? Its effect is three-fold:

- it gives better $R$ values than the data warrants.

- it confuses variables, making selection of important variables more difficult.

- errors in the 'rates' of Table 1 could be greater than those given by the MRA. 


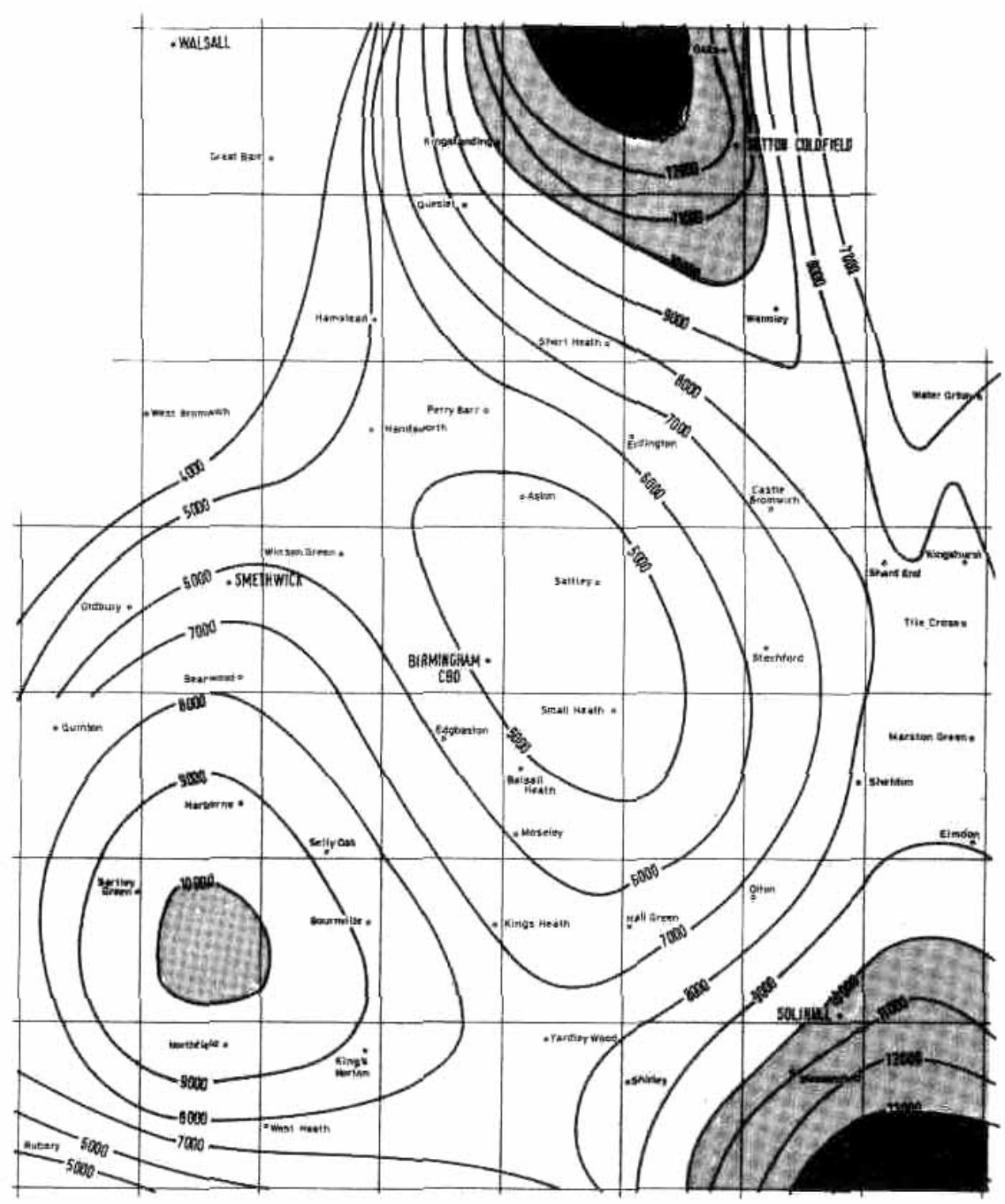

Figure 3 Contour map to show the effect of area on house prices. (Based on trend-surface analysis. Data for June 1979. Contours in $€$ ) 


\section{Table 1 Rates for the variables from MRA}

From the 519 property details, average values of 'rates' for each of the variables are produced, using the Multiple Regression Analysis computer package. $F$ value and *** indicate the importance of each variable.

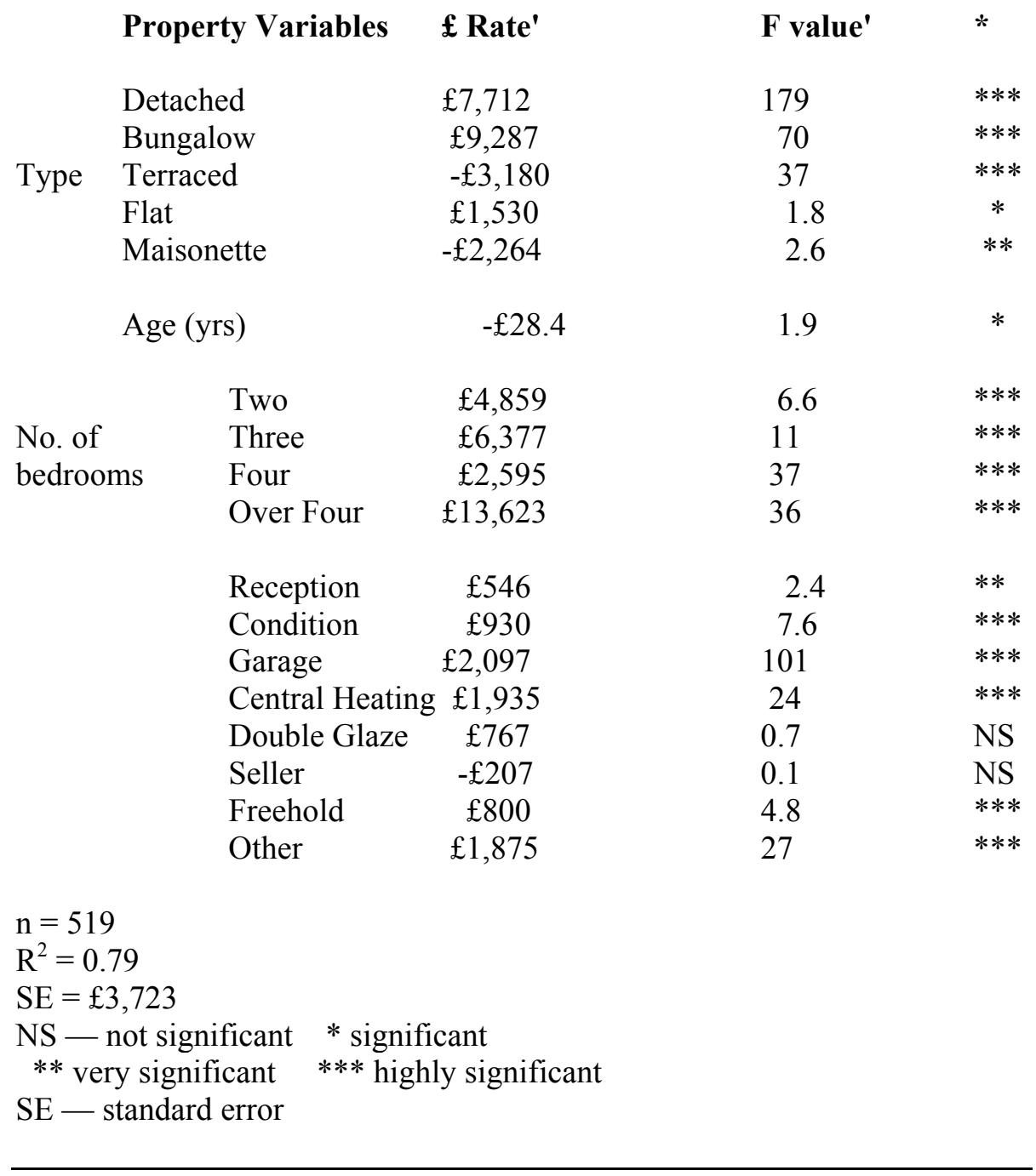

Thus it seems that because of multi-collinearity all MRA results are suspect. It certainly warns us to exercise caution. However, in the field of valuation all results can be subject to the test of both common sense and the market. So long as MRA gives useable results, it serves its purpose.

\section{Application of the expert system for valuation}

What has been described in this paper is essentially an 'academic' exercise, but with a practical end in view. As more valuation offices acquire microcomputers, then the opportunity for individual valuers to try out these techniques will arise. The first stage will probably be the computerisation of the 'comparable' records. The widespread availability of database programs makes this a relatively straightforward task. On its own this development promises great advances. One example is in the sorting of comparable data. 
A list in price order can prove extremely useful for valuations. But merely replicating existing filing systems using a computer is exploiting a very small part of the potential. Developing an expert system for valuation need not be the preserve of academics. Any valuer possessed of a computer and a logical turn of mind should be able to carry out the procedures outlined above. As more offices use micro-computers for routine storage of records, the biggest hurdle to the use of such techniques will be overcome. There will exist a large database of property transactions in machine readable form. From then on, the analysis presents no practical or time consuming difficulties. What could a practicing valuer expect to gain from developing his own expert valuation system?

An inestimable benefit will be the insight and objective knowledge he will gain from such a radical and novel analysis of his own data. To give but one small example from the MRA: a common belief is that ex-municipal properties command a lower price. MRA showed this not to be the case. Exmunicipal houses do not need a discount on the comparable non-municipal house value to make them saleable.

But the chief motivation for establishing an expert valuation system is, of course, to carry out valuations. As was seen from the example above, the results did not match up to the standard required. But even with this level of achievement, computerised valuations are worthwhile for a number of reasons:

- the computer can assist the valuer by giving a second opinion, or perhaps by giving a starting value. The results can set limits within which a valuation should fall. Any deviation from these limits could indicate a need for closer attention.

- in many situations, eg Building Society valuations, the need is not so much to estimate selling price, but to ensure that a minimum secure value exists. If the amount to be borrowed was less than (say) 60 per cent, then loans could be on the basis of computerised valuations alone (subject only to a check that the details given were correct - this would not need the skill of a valuer). The benefits to the Building Society and borrower are not only saving costs. Speed of decision can be crucial in obtaining the business; this was one of the main selling points in favour of the Banks during the mortgage glut of 1980-82.

- the expert system can act as a type of 'policeman', ensuring compliance with the correct procedures. This effect has been observed in medical and other expert systems. The fact that data has to be fed into a computer seems to sharpen the wits. It has been observed that death-rates declined with the introduction of computer diagnosis. Valuation offices, too, can expect an improvement in performance by using computerised valuations.

- professional negligence, especially following the Yianni case, is a matter of major concern to valuers. The fact that a computerized valuation was undertaken, could, in disputed cases, prove to be a very effective secondary defence. The print-out also has the merit of being tangible evidence, unlike the brain activity of the valuer, however competent he may have been. --consistency is guaranteed. Since the computer will always apply the same rules, it gives an identical answer given the same data. This corresponds to the notion of 'fairness', often important in valuations for compulsory purchase or sale of council houses. 


\section{Future developments}

As more valuers gain experience in using computerised valuations, the accuracy attained will undoubtedly improve. Indeed there might even be a danger that as more valuers turn to computerised valuations the results become a self-fulfilling prophecy. This is most unlikely, however. As different valuers develop varying models of price structure, so a continuing difference of opinion will persist. It also must be remembered that all valuations are subjected to the ultimate test in the market place.

One organisation from which a standard method of computerised valuations may emerge is the Inland Revenue valuation office. There is evidence to suggest that, in connection with capital value rating, the Inland Revenue have undertaken a number of studies, similar to the one described in this paper. With the resources at their disposal, it is to be hoped that they can develop a methodology which can givesufficient accuracy. It is also to be hoped that they publish at least the principles of any capital value rating method they adopt.

There are many technical problems still to be overcome in this new and exciting area of information technology. To mention some:

- What is the most effective model which adequately describes the variation of price with area?

- MRA is a statistical technique, which assumes a one-off test. But with computerised valuations there is a need to update the rates for variables. How can the previous results be combined with the latest values?

- what factors not included here are value significant? Plot size and frontage certainly have an effect, but how much? Is it possible to objectively rate the immediate environment of a property, including factors such as quality of adjacent houses, type of roadway, view? What effect has nearness of facilities such as shops, schools, pubs on value?

- if many valuers are going to undertake this sort of analysis, their endeavours will be greatly helped by a common coding scheme. The obvious candidate for such a profession-wide standard would be the classifications used by the Inland Revenue. But these are not on general release; in any event they were developed before the computer age and are probably inappropriate. The need for a common classification scheme still remains a matter of great urgency.

I look forward to a fruitful combined effort between academics, both in valuation and statistics, and valuation practitioners, in solving these and other problems. Whoever undertakes the research, the aim will remain the same: to produce an expert system capable of effectively carrying out valuations.

\section{References}

Baum, Andrew 'Extrapolating comparable evidence', Estates Gazette, 263: 23, 3rd July, 1983

Byrne, P. J. and Bowcock, P. 'The structure of residential property values in St Albans', University of Reading (1973)

Doling, John 'The use of content analysis in identifying the determinants of house prices',Urban Studies, Vol. 15, pp. $89-90$ (1978)

Doling, John and Davies, Mary 'Fair rents and capital values', Estates

Gazette, 260: 677,14th November, 1981 
Grillches, Zvi 'Hedonic price indices revisited: some notes on the state of the art', Proc. Amer. Stat. Assoc. (1967)

Huang, David S. Regression and Econometric Methods, Wiley, New York (1970)

Imam, R. L. and Conover, W. J. Modern Business Statistics, Wiley, London (1983)

Johnson, N. L. and Leone, F. C. Statistics and Experimental Design, Vol. 2, Wiley, London(1977)

Lansdown, J. 'Expert systems: a memorandum on their scope and use', BOCAAD (Bull.Comput. Aided Architectural Des.) (GB) Vol. 38, pp. 25-36 (1980)

Lawrence, D. M., Rees, W. H. and Britton, W. 'Modern methods of Valuation of Land, Housesand Buildings', Estates Gazette, London (1971)

Lindberg, D. A. B. et al 'Computer based rheumatology consultant', Proc. 3rd World Conf. onMedical Informatics, Tokyo (1980), North-Holland, Amsterdam (1980)

MacLennan, D. 'Some thoughts on the nature and pupose of house price studies', Urban Studies, Vol. 14, pp. 59-71 (1977)

Michalski, R. S. and Chilausky, R. L. 'Learning by being told and learning from examples: anexperimental comparison of the two methods of knowledge acquisition in the context of developing an expert system for soyabean disease diagnosis', Int. J, Policy Anal, and Inf.

Syst. (USA), Vol. 4, No. 2, pp. 125-61 (1980)

Michie, Donald (ed) Expert Systems in the Micro-electronic Age, Edinburgh Univ. Press,Edinburgh (1979)

Millington, A. F. 'An Introduction to Property Valuation', 2nd ed., Estates Gazette, London(1982)

Richardson, H. W., Vipond, J. and Furbey, R. A. Housing and Urban Spatial Structure: a CaseStudy, Saxon House, Farnborough (1975)

Shenkel, William Modem Methods of Real-Estate Appraisal, McGraw-Hill, New York (1978)

Wood, E. A. 'Current developments in property valuation and appraisal', Seminar at Liverpool Polytechnic, 7th February, 1973, reported in The Valuer

\section{General references: valuation and MRA}

Ball, Michael J. 'Recent empirical work on the determinants of house prices', Urban Studies, Vol. 10, pp. 213-33 (1973)

Blettner, Robert A. 'Mass appraisals via multiple regression analysis', The Appraisal Journal,pp. 513-21 (October, 1969)

Bowcock, Philip 'Capital values for dwelling houses', Rating and Valuation, pp. 173-75(June, 1981)

Chudleigh, Walter M. 'The application of correlation matrix analyses to real estate appraisal',The Appraisal Journal, pp. 523-30 (October, 1979)

Griffin, Gerald 'Conventional appraisal techniques can be computerized', The Appraisal Journal,pp. 253-62 (April, 1979)

Kamath, Ravindra R. and Yantek, Kenneth R. 'Linear multiple regression analysis applied to valuation of single family homes', The Real Estate Appraiser and Analyst, pp. 36-41(September-October, 1979)

Lessinger, Jack 'Econometrics and appraisal', The Appraisal Journal, pp. 501-12 (October, 1969)

Lessinger, Jack 'A"final" word on multiple regression and appraisal', The Appraisal Journal,pp. 449-61 (July, 1972) 
Smith, David V. 'An appraiser looks at multiple regression', The Appraisal Journal, pp. 248-52(April, 1979) 